\title{
In Search of Prediction Factors for Autism Spectrum Disorders: An Impossible Task?
}

\author{
René Pry ${ }^{1}$, Arne F. Petersen ${ }^{2}$, Amaria Baghdadli ${ }^{3}$ \\ ${ }^{1}$ Université Paul Valéry \& CHU-Montpellier, Montpellier, France \\ ${ }^{2}$ Centre de Ressource Autism, CHU-Montpellier, Montpellier, France \\ ${ }^{3}$ Child \& Adolescent Psychiatry, CHU-Montpellier, Montpellier, France \\ Email: rené.pry@univ-montp3.fr
}

Received September $26^{\text {th }}, 2012$; revised October $21^{\text {st }}, 2012$; accepted November $16^{\text {th }}, 2012$

\begin{abstract}
Clinical work and prediction of development are closely linked in the practice of early detection, diagnosis and choice of modes of intervention in young children with autism. Variables are often defined in terms of risk factors or of development, and may refer to general or specific phenomena. The purpose of this paper was, using a generalized mixed model, to test ways of measuring development and its prediction regarding joint attention (that is to say, response to and initiation of joint attention) in children with autism. Over a period of one year, seventy-seven children were followed from the age of four and a half years upwards. The results show that it is possible to identify general risk factors, but much more difficult to pinpoint specific factors. In our current state of knowledge, prediction can only be of a global nature and therefore requires the use of general markers.
\end{abstract}

Keywords: Autism; Joint Attention; Prediction; GLMM; Risk Factor; General Marker

\section{Introduction}

A major part of the research and clinical work on children with pervasive developmental disorders is devoted to the question of prediction. Prediction is already implied in the early detection of the syndrome, but it becomes a special developmental problem once the diagnosis has been established, and it is finally evoked when treatment strategies are chosen. So far experience has shown that within these three domains the prognosis is not only uncertain but virtually impossible.

\section{Possible Prediction Factors-An Overview}

Prediction factors are usually considered in two perspectives: 1) From a developmental (temporal) viewpoint, opposing risk factors and developmental factors; and 2) From a clinical viewpoint which distinguishes global factors and specific factors.

1) Developmental perspective. Risk factors may be subdivided into primary, secondary, tertiary etc. factors - a classification which divides the pre-diagnostic period (for autism the first 30 months) into periods during which new competences known as normal development are expected to occur. Developmental factors are generally evoked from the time of diagnosis, which is also the starting point for most longitudinal studies.

2) Clinical perspective. Global or general markers for autism relate to the diagnosis, which is itself an outcome of composite evaluations like the ADI (Lord, Rutter, \& Le Couteur, 1994, 2010), ADOS (Lord, Risi, Lambrecht, Cook, Leventhal, DiLavore, Pickles, \& Rutter, 2000, 2010), or refer to the severity of the disturbance, which is also a result of composite assessments (CARS: Schopler, Reichler, DeVellis, \& Daly, 1980), and other indices of gravity, IQ, as well as general markers for socio-adaptability like those in Daily Living Skills (DLS) of the Vineland Scale (Sparrow, Balla, \& Cicchetti, 1984). These global scores possess emergent qualities which transcend the sub-scores they consist of (thus the whole does not equal the sum of its parts). Being real synthetic scores they express a clinical reality, that of the autistic syndrome. Specific or elementary markers, which refer to certain competences (such as synchronous imitation, joint attention, identification of facial expressions, prosodic modulation, vocabulary, etc.), are unfortunately more often than not coded in terms of "present/ absent", or marked "positive/negative", even though their development may start discretely as precursor indices for global markers (Nadel, 2009).

Here it is noteworthy that, if we attribute a certain predictive value to these different factors, naturally we also have to ascribe to them a certain stability over time, or consider them as stable characteristics for individuals with autism.

By crossing the two main classifications we obtain a combination of prediction factors from which it is possible to articulate the developmental and clinical perspectives (Table 1).

But before addressing this question it is appropriate to note that various constraints complicate the very identification of the different factors. Among these constraints we shall consider the following: definition of the disorder (a complex and multifarious phenomenon), its changing prevalence, the question of time-independence of the prediction factors, and the choice of statistical methodology.

\section{A Global Definition}

For the whole group of pervasive developmental deficits (PDD) the World Health Organisation's ICD-10 classification (1994) is the most recommended. PDD includes various clinical 
Table 1.

Factors and variables used in prediction studies.

\begin{tabular}{|c|c|c|c|}
\hline & Factor & Elementary & Global \\
\hline \multirow{6}{*}{ Explanatory variables } & \multirow{5}{*}{ Risk } & Social smile & Genetic load \\
\hline & & Reaction to call-name & Neonatal history \\
\hline & & Joint attention & Sensorial reactivity \\
\hline & & Fantasy play & Tonico-postural regulation \\
\hline & & Productive lexicon & Spontaneous motor activity \\
\hline & Developmental & $\begin{array}{l}\text { Special treatment program } \\
\text { Delay/specific hyper competence }\end{array}$ & $\begin{array}{l}\text { Diagnostic markers } \\
\text { Associated disorders } \\
\text { Intensity of the treatment } \\
\text { Intellectual level }\end{array}$ \\
\hline \multirow{3}{*}{ Variables to be explained } & \multirow{3}{*}{ Prediction } & Linguistic activity & Clinical development \\
\hline & & Interactive competences & Psycho-social development \\
\hline & & Behavioural disorders & Everyday autonomy \\
\hline
\end{tabular}

phenomena, which may be divided into seven categories (infantile autism, atypical, Rett, disintegrative, hyperkinetic with mental retardation, Asperger and others) or in a dimensional respect (the notion of Autism Spectrum Disorders: ASD). These two approaches cover the same clinical reality: they identify qualitative and simultaneous impairments, reciprocal social interactions, modalities of communication, as well as a repertoire of interests and limited stereotyped, repetitive activities. This combination, which founds the notion of "disorder", cannot be merely fortuitous. As a consequence, this very association translates itself in reality by a multitude of formulations, in terms of intensity or predominance of one impairment over another, or again by a more or less discrete presence of diagnostic criteria (age, ...).

It is evident that this phenomenon, being multifarious indeed, may easily be the phenotypic expression of the same disorder with different severity or signal several independent deficits. Besides the ICD, which is an ongoing classification, foresees that within one and the same category new deficits may appear, and that in future editions other categories may be formed.

\section{Weak Prevalence and Prediction Factors That Change with Time}

For a long time pervasive developmental disorders were considered for a long time considered to be a statistically rare phenomenon (4 in 10,000). Today, however, the prevalence is 6 to 7 for 1000 individuals under 20 years of age, and for autism 2 to 4 for 1000 individuals (Charman, 2002; Fombonne, 2009). The accuracy of identifying of risk factors depends on the prevalence in so far as a weak prevalence produces a large number of "false positives". This phenomenon can be illustrated by some working data which we now have at our disposal in a precocity survey for which there is high specificity $(=.98)$, but low sensitivity and a large number of "false positives" (=.38) as in the "Check-List for Autism in Toddlers" (Baron-Cohen, Wheelwright, Cox, Baird, Charman, Swettenham, Drew, \& Doehring, 2001) and in the "Modified CheckList for Autism in Toddlers" (Robins, Fein, Barton, \& Green, 2001; Baghdadli, 2005).

While, in some cases, predicting a given illness or disorder may not be too difficult, since the risk factors have been easily identified (linked, say, to genes, nutritional problems, radiation exposure), it is quite another matter with pervasive developmental disorders for which many factors will be in interaction and probably of a genetic, neurological or environmental na- ture.

Since the ways in which the risk factors are expressed change with the child's development and only become somewhat stabilised when the child approaches 36 months of age, it seems only possible to pronounce a reasonable diagnosis at this time of maturation. By this we mean that the general markers, which are present from early on, undergo differentiation and seemingly end up "coinciding" with the characteristics of the disorder. For practical reasons it may be helpful to break down and analyse the risk factors in view of a temporal organisation for normal development during the sensorimotor period: 1) The neonatal and perinatal phase; 2) The 2-month-old phase (with social smile, intentionality and interplay with a partner); 3) A phase at nine months (when triadic competences and joint attention appear); and 4) A phase at eighteen months (when the symbol function emerges) (Rochat, 2001). For each of these phases the particularities of children with PDD may then be noted, such as missing or non-developed abilities, regression or temporary disappearance of skills, etc.

The only risk factors for PDD bearing upon the neo- and perinatal phase, which have been identified so far, are those of sex-ratio (four times more common in boys than in girls), the age of the parents (the risk is multiplied by 1.3 for mothers over 35 years of age and by 1.4 for fathers aged over 40 ), the presence of another affected child among the siblings (4\% higher risk if the affected child is a boy, and $7 \%$ higher risk if it is a girl). The risk strongly increases $(25 \%$ to $30 \%)$ if the family already includes two children with PDD, and the syndrome concordance between monozygote twin boys varies from $70 \%$ to $90 \%$. Finally, it seems that incidences of pre- and perinatal antecedents are more common in individuals with PDD than in the population as a whole.

Retrospective studies, especially those that include analyses of family films, have also revealed unusual behavioural traits, first and foremost in spontaneous motricity (Rogers \& Beneto, 2002; Fournier, Hass, Naik, Lodha, \& Cauraugh, 2010), but also in variations of tonus and peculiarities in sensory and attention processing. However, these markers remain very general and not functionally specific, even though they may derive from a particular sensorimotor functioning, and at present we do not dispose of enough relevant statistical data on prevalence, sensitivity and specificity. Results of longitudinal studies, from the age of 12 months, on brothers and sisters, born after a sibling with autism, attach a tentative predictive value to the absence or rareness of social smile, eye contact, and orientation 
when being called (Yirmiya, Gamliel, Pilowsky, Feldman, Baron-Cohen, \& Sigman, 2006).

On the other hand, research based on questionnaires has identified tertiary risks between 18 and 24 months such as passivity and low level of reactivity to social stimuli, difficulties with visual following and joint attention, retarded expressive language (in particular, absence of proto-declarative and demonstrative gestures), no real fantasy play.

\section{Stability and Instability of Developmental Factors}

Even though the number of interacting factors of development is considerable, it has nevertheless been possible to classify variables such as the conditions of appearance and precociousness of the disorders, their importance in terms of symptom intensity, the presence of associated troubles (intellectual deficiency, epilepsy, somatic pathologies), and environmental factors. Among the latter, certain modalities of care and support seem to be of importance, although, even today, it is difficult to evaluate the exact impact of treatment on development; this being said, some results lead us to think that precocity, intensity of the proposed stimulation, and structural adaptation of the environment may be of positive influence (Montreuil \& Magerotte, 1994; Recordon-Gaboriaud, 2009).

In fact, the factors that best account for socio-cognitive development in autism are general markers derived from development quotients, e.g. IQ, established by evaluations on different levels of development regarding adaptive functions assessed at the time of diagnosis. These general markers are composite and come from very heterogeneous developmental domains (motor, cognitive, social, linguistic, etc.). In every second child with autism, the scores of the intelligence test increase significantly with age (Pry, Juhel, Bodet, \& Baghdadli, 2007). Moreover, between childhood and adulthood a tendency towards a decrease in the "non-verbal" component can be observed in tempo with a moderate increase in the "verbal" component (Seltzer, Shattuck, Abbeduto, \& Greenberg, 2004; Mawhood, Howlin, \& Rutter, 2000). It should also be noted that in children with "IQ-extremes" like $<50$ and $>100$ one observes a more disadvantageous prediction than in the population with IQ's $<100$ and $>50$. Likewise, the presence of language in production - even when starting very late-is always a positive prognostic factor. However, as mentioned before, the only variable which shows some stability is the diagnosis, but this remains unchanged for life in $80 \%-96 \%$ of the cases studied (Seltzer et al., 2004).

Finally, we should not forget that often the choice of variable to be explained also is of a general nature ("good"/"bad") or the variable is described in a categorical manner from criteria such as attainment of everyday autonomy. Studies in which the objective is the onset of specific competences are much rarer.

\section{Statistical Constraints}

Three major classes of model are employed for making the prediction: linear regression and generalised linear models (logistic regression and Poisson regression). Linear regression leads to a generalised notion of correlation and of t-test; logistics regression results in a generalisation of the notion of oddsratio and the Chi-2 test. A third class of model appears (which is the object of this paper), namely the generalised linear model mixed with repeated measures (GLMM) (Breslow \& Clayton,
1993; Fitzmaurice, Laird, \& Ware, 2004).

In linear regression the nature of the explicative variables (qualitative dichotomies) lend themselves very well to techniques like ANCOVA. In this kind of approach the "regression diagnosis" is important: the variable to be explained must be quantifiable, the residua $e_{i}$ must follow a normal law and be independent, the explicative variables must not be redundant, and the robustness of the model must be tested (ruling out the extreme cases). In practice, and more precisely in developmental psychopathology, these conditions are rarely united, and we often see situations of multi-linearity between prediction factors.

In logistic regression the variables may be qualitative (in general binary), multi-nominal (when there are more than two classes), or enumerative (e.g. number of hours of treatment) as in the Poisson regression model. These models are sufficiently adapted to the complex problem of prediction for linking up a diagnosis or a development (binary variable) with a group of risk factors with which one tries to characterise the respective weights. The strength of such links may be expressed in terms of excess risk, relative risk, "odds ratio", or attributive risk.

The characteristics of "regression diagnosis" are the independence of residues, the detection of "likely" subjects, at the origin of important variations (robustness of the model) and the search for multi-linearity.

Generalised linear models mixed with repeated measures are techniques with a theory of high content and much in use: these techniques are applied in areas as diverse as forestry, medicine, finance, economy, industry and so forth. They are most interesting since they can be used to analyse diverse effects and repeated measurements, and they are ready for use with different probability laws with a view to modelling errors, and even more so as their distributions belong to the exponential family (which is often found in developmental psychology).

On the basis of all these remarks one may ask how the interactions between the different classes of variables take place over a given period (does a predictive variable at a given time explain the same percentage of variance later on?)-i.e. the developmental perspective - and to question whether the data collected at the moment of the diagnosis are informative with respect to a specific competence-i.e. the clinical perspective.

\section{Methodology: Population Characteristics, Developmental Factors and Target Variables}

The present study was coordinated by the LanguedocRoussillon Autism Resource Centre at the CHU in Montpellier. Seventy-seven children with autism were examined three times at intervals of 6 months: T1, T2 (T1 +6 months) and T3 (T1 + 12 months).

The diagnoses were worked out on the basis of pluridisciplinary, clinical observations guided by the standardised version of international classifications of mental and behavioural disorders (ICD-10, WHO, 1994) and by using the "Revised Autism Diagnostic Interview” (Lord, Rutter, \& Le Couteur, 1994), ADOS (Lord, Risi, Lambrecht, Cook, Leventhal, DiLavore, Pickles, \& Rutter, 2000) and the "Childhood Autism Rating Scale" (Schopler, Reichler, DeVellis, \& Daly, 1980). Children with pronounced motor delay on levels less than 18 months were not included, as the aspects of retardation, by increasing the prediction, may hide the variability of the rest of the sample. 
A descriptive analysis of the population of 77 children was carried out by calculating the frequency of the quantitative variables, the median and the interquartiles $(75 \%$ and $25 \%)$ for the qualitative variables (their distribution not always being Gaussian, the normality of the distributions was analysed with the help of the Shapiro-Wilks Test).

The sample presented two diagnostic categories: $87 \%$ (67) of the children suffered from infantile autism and $13 \%$ (10) from atypical autism. It included 66 boys (86\%) and only 11 girls (14\%): thus the sex-ratio is $6 / 1$ which was slightly above the ratio found in epidemiological studies, whose only inclusion criterion is the diagnosis of autism or that of other PDDs. In return this result is in agreement with those obtained in populations with autism without mental retardation. The median age at the beginning of the observation period was 52 months with an interval included between 35 months for the youngest child and 60 months for the oldest child and an interquartile $25 / 75$ between 48 and 59 months. The level of expressive language was assessed with item 19 of the ADI-R: $(0=$ production of phrases; 1 = fewer than 50 words; $2=$ fewer than 5 words). The two main forms of motor development (global and fine) were explored with the two revised Brunet-Lézine subscales: oculomanual coordination and postural development. Regarding motor development, the median level of oculo-manual coordination was 20 months with an interquartile included between 18 and 24.5 months, and the median postural level was evaluated as being around 24 months with an interquartile included between 20 and 30 months. These data are presented in Table 2.

The levels of socio-adaptive development were assessed by the Vineland Scale or VABS (Sparrow, Balla, \& Cicchetti, 1984). This scale evaluates the children's adaptation level in the functional domains of communication, socialisation, autonomy in everyday life, and motor development. The American norms of the Vineland Adaptive Behaviour Scale also apply to the French population (Fombonne \& Achard, 1993; Pry, Guillain, \& Foxonet, 1996), and there is a specific standardisation for sub-populations with autism (Carter, Volkmar, Sparrow, Wang, Lord, \& Dawson, 1998; Freeman, Delhomme, Guthrie, \& Zhang, 1999).

The variable to be explained was joint attention, which was assessed by using the ECSP-Scale (Guidetti \& Tourette, 1993), adapted to the Early Social Communication Scale (Seibert \& Hogan, 1982). This last scale evaluates the development of skills for establishing shared attention to the same object, person, event or topic. Two kinds of reactions were studied: 1) Response to joint attention. The aim here was to describe the

Table 2.

Characteristics of the sample at $\mathrm{T} 1$.

\begin{tabular}{|c|c|c|c|}
\hline Variable & & $\begin{array}{l}\mathbf{N} \\
77\end{array}$ & $\begin{array}{l}\% \\
100\end{array}$ \\
\hline Diagnosis & $\begin{array}{l}\text { Typical } \\
\text { Atypical }\end{array}$ & $\begin{array}{l}67 \\
10\end{array}$ & $\begin{array}{l}87 \\
13\end{array}$ \\
\hline Age (months) & $\begin{array}{l}\text { Median } \\
25 \%-75 \% \text { percentile }\end{array}$ & $\begin{array}{l}52 \\
48-59\end{array}$ & \\
\hline Age at detection ${ }^{*}$ (months) & $\begin{array}{l}\text { Median } \\
25 \%-75 \% \text { percentile }\end{array}$ & $\begin{array}{l}16 \\
8.75-24\end{array}$ & \\
\hline Sex & $\begin{array}{l}\text { Male } \\
\text { Female }\end{array}$ & $\begin{array}{l}66 \\
11\end{array}$ & $\begin{array}{l}85.7 \\
14.3\end{array}$ \\
\hline SPC $^{* *}$ & $\begin{array}{l}\text { Low } \\
\text { Average } \\
\text { High }\end{array}$ & $\begin{array}{l}13 \\
23 \\
41\end{array}$ & $\begin{array}{l}16.9 \\
29.9 \\
53.2\end{array}$ \\
\hline & $\begin{array}{l}\text { Median } \\
25 \%-75 \% \text { percentile }\end{array}$ & $\begin{array}{l}24 \\
18-31\end{array}$ & \\
\hline CARS & $\begin{array}{l}\text { Median } \\
25 \%-75 \% \text { percentile } \\
\text { Communication }(\geq 8)^{* * *}\end{array}$ & $\begin{array}{l}33 \\
26.5-36.5 \\
69\end{array}$ & 93 \\
\hline ADI-R & $\begin{array}{l}\text { Social interactions }(\geq 10) \\
\text { Few interests }(\leq 3) \\
\text { Anomalies before } 36 \text { months }(\geq 1)\end{array}$ & $\begin{array}{l}71 \\
65 \\
74\end{array}$ & $\begin{array}{l}96 \\
88 \\
100\end{array}$ \\
\hline $\begin{array}{l}\text { ADOS-G } \\
\text { Module } 1\end{array}$ & $\begin{array}{l}\mathrm{N} \\
\text { Social interactions: } \mathrm{m}(\mathrm{sd}) \\
\text { Repeated behaviour } \\
\mathrm{N}\end{array}$ & $\begin{array}{l}57 \\
15.08(4.8) \\
3.67(1.58) \\
20\end{array}$ & 74 \\
\hline Module 2 & $\begin{array}{l}\text { Social interactions: } \mathrm{m}(\mathrm{sd}) \\
\text { Repeated behaviour }\end{array}$ & $\begin{array}{l}13.92(4.1) \\
2.67(1.4)\end{array}$ & 26 \\
\hline & Good: Phrases: N (\%) & 20 & 26 \\
\hline Expressive language: & Middle: $>5$ words & 20 & 26 \\
\hline Item 19 ADI & Poor: $<5$ words & 37 & 48 \\
\hline $\begin{array}{l}\text { Visual-manual coordination }{ }^{* * * *} \\
\text { Postural level }\end{array}$ & $\begin{array}{l}25 \%-75 \% \text { percentile } \\
\text { Median } \\
25 \%-75 \% \text { percentile }\end{array}$ & $\begin{array}{l}18-24.5 \\
24 \\
20-30\end{array}$ & \\
\hline
\end{tabular}

*Age at which the first disturbances were recognized; ${ }^{* *}$ Parents' socio-professional category: Low (workers, farm workers); Average (middle class, employees, farmers); High (industrial, business, and intellectual professions, heads of company or business); ${ }^{* * *}$ Algorithm threshold; ${ }^{* * * *} \mathrm{BL}-\mathrm{R}$. 
development of the child's understanding of the attempts by an adult to direct his attention towards an object and his abilities to understand and follow the adult's indication. Thus, the right response to most items was to look at and touch, to point to or take hold of what the adult had been attending to. To name and comment on objects in reply to an adult's questions appear when the child starts talking on the higher level in a series of 5 levels: simple, complex, conventional gestures, conventional verbal and symbolic utterances. 2) Initiation of joint attention. The aim of this observation series was, firstly, to describe the child's growing awareness that an adult may attend to the same object or event as he himself is attending to, and, secondly, to describe the development of means which a child may use to direct an adult's visual attention to an object or event and make the adult attend to what he is himself just looking at. Such attempts, which must appear spontaneously, can also be divided into 5 levels.

In children with typical development the joint attention skill may be located between 6 and 12 months implying an interaction with others. It reveals itself in pointing and checking the direction of the other's glance, and among the precursors of these abilities is the capacity to detect the direction and target of another's glance. In children with autism this initial capacity is much retarded, and when they start walking the deficits they manifest with joint attention are remarked the most (BaronCohen, 1989; Jones \& Carr, 2004; Nichols, 2005; Mundy, 2007). The response and initiation of joint attention are associated with the emergence of receptive and expressive language and deserve particular interest since their later development turns out to be a predictive variable in itself. The scores of the Vineland Scale (in months) and those of joint attention, distributed according to the three observation periods, are shown in Table 3.

\section{Results}

A technique for generalised linear models mixed with repeated measurements was used for data processing (Statistica, v.9). The regression was carried out in an exhaustive search for the best model and by crossing two criteria: the standardised AKAIKE information criterion (AIC) and the Bayesian de Schwarz-criterion. The explicative variables introduced into the model were as follows: the category of diagnosis, age at T1, age when the disorder was discovered, the parents' socio-professional category (SPC), sex, intensity of the disorder at T1, initial language level at T1, and the levels of adaptive behaviour at T1, T2, and T3. The values of the two explicative variables, at the three times, were also introduced into the model, and a descending procedure of a step-by-step nature was then undergone.

Regarding the response to joint attention, the prediction values brought about by the most satisfactory model $(\sim<5$ words $+>5$ words. Autism + CARS + Phrases. T2 + Phrases. T3 + $(1 / \mathrm{NUM}))$ are shown in Table 4 . The model for the variable to be predicted is not linear but of the Poisson family (log link) (see Table 4). The variables which seem to have a positive in-

Table 3.

Median development of adaptive behaviour and joint attention (Interquartiles Q25-Q75).

\begin{tabular}{|c|c|c|c|}
\hline & T1 & T2 & T3 \\
\hline \multirow[t]{2}{*}{ Communication } & $18^{*}$ & 19 & 24 \\
\hline & $(14-22)$ & $(15-30)$ & $(16-35.5)$ \\
\hline \multirow[t]{2}{*}{ Autonomy } & 27 & 29 & 31 \\
\hline & $(21-32)$ & $(21-35)$ & $(24-39)$ \\
\hline \multirow[t]{2}{*}{ Socialisation } & 19 & 22 & 25 \\
\hline & $(12-25)$ & $(16-35)$ & $(15.5-39)$ \\
\hline \multirow[t]{2}{*}{ Motor behaviour } & 32 & 37 & 41 \\
\hline & $(24-39)$ & $(29-43)$ & $(32-51)$ \\
\hline \multirow[t]{2}{*}{ Response to joint attention } & $8^{* *}$ & 10 & 11 \\
\hline & $(36-14)$ & $(5-16)$ & $(5-17)$ \\
\hline \multirow[t]{2}{*}{ Initiation of joint attention } & 5 & 6 & 6 \\
\hline & $(4-8)$ & $(4-9)$ & $(4-10)$ \\
\hline
\end{tabular}

"Developmental age; ${ }^{* *}$ Raw score.

Table 4.

Prediction and behavioural response to joint attention.

\begin{tabular}{lccccc}
\hline & Estimation & Standard errors & Value of $\mathbf{z}$ & $\operatorname{Pr}(>/ \mathbf{z} /)$ & Significance \\
\hline Order at onset & 3.85 & .24 & 15.79 & $<2^{\mathrm{e}}-16$ & .000 \\
$<5$ words & -.99 & .15 & -6.74 & $1.62^{\mathrm{e}}-11$ & .000 \\
$>$ 5 words ${ }^{*}$ Autism & -.65 & .14 & -4.74 & $2.21^{\mathrm{e}}-06$ & .000 \\
Intensity & -.04 & .01 & -4.48 & $4.40^{\mathrm{e}}-06$ & .000 \\
$<5$ words ${ }^{*}$ Tps2 & .27 & .11 & 2.44 & .015 & .05 \\
$<5$ mots ${ }^{*}$ Tps3 & .24 & .11 & 2.23 & .02 & .05 \\
\hline
\end{tabular}

AIC: 359; BIC: 383.1; LogLik: -172.5; Deviance: 345 . 
Table 5.

Prediction and behavioural initiation of joint attention.

\begin{tabular}{|c|c|c|c|c|c|}
\hline & Estimation & Standard errors & Value of $z$ & $\operatorname{Pr}(>/ \mathbf{z} /)$ & Significance \\
\hline Order at onset & 2.79 & .15 & 18.2 & $<2^{\mathrm{e}}-16$ & .000 \\
\hline$<5$ words & -.69 & .08 & -8.08 & $6.68^{\mathrm{e}}-16$ & .000 \\
\hline$>5$ words $^{*}$ Autism & -.46 & .09 & -5.28 & $1.27^{\mathrm{e}}-07$ & .000 \\
\hline Intensity & -.02 & .00 & -3.35 & $-.81^{\mathrm{e}}-5$ & .000 \\
\hline
\end{tabular}

AIC: 193.8; BIC: 211; LogLik: -91.9; Deviance: 183.8 .

fluence on the development of joint attention are the following: absence of language, alone or associated with the diagnosis of typical autism (versus atypical autism), initial intensity of the disorder, and, finally, a time effect which may be considered as a factor uniting maturation with life experience. Three variables $(<5$ words, Autism diagnosis and intensity) seem to restrain development of joint attention (aggravating factors). On the other hand, for children with an elaborate, initial linguistic activity (presence of phrase production), we noted a significant improvement in this skill at T2 and T3, whereas the improvement between $\mathrm{T} 1$ and $\mathrm{T} 2$ was not significant (protection factors).

Regarding the abilities for initiating joint attention, the prediction values brought about by the most satisfactory model $(\sim<5$ words $+>5$ words. Autism + CARS $+(1 / \mathrm{NUM}))$ are shown in Table 5. The only variables retained turned out to have a significantly negative effect on the development of initiation of joint attention (aggravating factors). These were: no language production, autism diagnosis when accompanied by language beginning (lexicon of $>5$ words), and initial intensity of the disorder. On the other hand, time did not seem to have an improving influence on the performances and no variables appeared which could have played a positive role (protection factors) appeared.

In these two versions of joint attention - the first, to understand and respond to the initiation of shared behaviour, and the second, to initiate the very same behaviour oneself - neither the adaptive behaviour of communication activities and DLS, nor the motor behaviour had any effect upon the development of the two facets of this skill. It is appropriate to remember (see Table 2) that these behaviours become complex with time (the differences in performance between $\mathrm{T} 3$ and $\mathrm{T} 1$ are significant in the four domains), and that for most of them it depends on the behaviour being learnt. We may speculate that the constraints on these two developments - adaptive behaviour and joint attention, and the mechanisms at their basis - will be of a different nature, at least at this age and in children with autism.

\section{Discussion}

Several questions arise concerning the interpretation of these results. Among the factors retained, the majority of them appear to be risk or aggravating factors registered clinically as negative signs which forecast a delay or "non-appearance" of one or more skills: no productive language, most severe diagnosis, high disorder intensity. Only one of these factors is really specific for autism: that of the "typical autism" diagnosis; the other factors may be found in intellectual deficiency and/or in specific language disorders. Moreover, they all accompany global developmental delay. They are, however, extremely general markers and none of them belong in any specific way to the chain of development that leads to the complex coordination constituting joint attention (awareness of self, imitation, visual face-perception, selective attention, sharing, etc.) Yet they endorse the liaison between linguistic activity and joint attention.

Among the other variables introduced into the model, such as sex, levels of communication, socialisation or everyday adaptation, of which we might expect a somewhat close affiliation with the target variable, none of them had any predictive character. Thus we must admit that whatever methodological sophistication is used, we are left with extreme generalities such as: an overall delay "produces" certain specific delays and/or is predictive of specific delays, except for small groups of children with certain language competences.

Perhaps these kinds of delay, like the qualitative impairments in development are, at the same time, the characteristics and the specificity of the autistic disturbance at the time of diagnosis. It is perhaps also the period in the development of the individual when the disturbance is the most pervasive, as it simultaneously affects major functions like communication and socialisation, and limits the taste for novelty - and, in so doing, limits the possibilities of prediction.

\section{Conclusion}

Should we then conclude that any prediction in autism is impossible? That the current formulation of the disorder, which is of a behavioural nature, is an epistemological obstacle for all prognostic activity, since the pathology is complex and developmental? Perhaps the normal approach, which consists of searching for precursor elements that may define PDD (limitation of interest, motor expressivity, proto-language), is not the best solution? It remains possible that today the very general markers are the best synthesis of these characteristics to come. The counterpart of this attitude is that we should not reduce autism spectrum disorder to a mere formulation of deficits. After all, autism is an original development, a queer construction, with astonishing ways of processing information, whether social or not, which may also lead to hyper competences.

\section{REFERENCES}

Baghdadli, A. (2005). Recommandations pour la pratique professionnelle du diagnostic de l'autisme. Fédération française de Psychiatrie. Haute Autorité de Santé, Paris, Saint-Denis la Plaine: FFP; HAS.

Baron-Cohen, S. (1989). Joint attention deficits in autism: Towards a cognitive analysis. Development and Psychopathology, 1, 185-189. doi: $10.1017 /$ S0954579400000377

Baron-Cohen, S., Wheelwright, S., Cox A., Baird, G., Charman, T., Swettenham, J., Drew, A., \& Doehring, P. (2000). Early identification of autism by the Checklist for Autism in Toddlers (CHAT). Journal of the Royal Society of Medicine, 93, 521-525.

Breslow, N. E., \& Clayton, D. G. (1993). Approximate inference in 
generalized linear mixed models. Journal of the American Statistical Association, 88, 9-25. doi:10.2307/2290687

Carter, A. S., Volkmar, F. R., Sparrow, S. S., Wang, J. J., Lord, C., Dawson, G. et al. (1998). The vineland adaptive behavior scales: Supplementary norms for individuals with autism. Journal of Autism and Developmental Disorders, 28, 287-302. doi:10.1023/A:1026056518470

Charman, T. (2002). The prevalence of autism spectrum disorders. Recent evidence and future challenges. European Child and Adolescence Psychiatry, 11, 249-256. doi:10.1007/s00787-002-0297-8

Esbensen, A. J., Seltzer, M. M., Lam, K. S., \& Bodfish, J. W. (2009). Age-related differences in repetitive behaviors in autism spectrum Disorders. Journal of Autism and Developmental Disorders, 39, 5766. doi:10.1007/s10803-008-0599-x

Fitzmaurice, G. M., Laird, N. M., \& Ware, J. H. (2004). Applied longitudinal analysis. Hoboken, NJ: Wiley-Interscience.

Fombonne, E. (2009). Epidemiology of pervasive developmental disorders. Pediatric Research, 65, 591-598. doi:10.1203/PDR.0b013e31819e7203

Fombonne, E., \& Achard, S. (1993). The vineland adaptive behavior scale in a sample of normal french children: A research note. Journal of Child Psychology and Psychiatry, 34, 1051-1058. doi:10.1111/j.1469-7610.1993.tb01108.x

Fournier, K. A., Hass, C. J., Naik, S. K., Lodha, N., \& Cauraugh, J. H. (2010). Motor coordination in autism spectrum disorders: A synthesis and meta-analysis. Journal of Autism and Developmental Disorders, 40, 1227-1240. doi:10.1007/s10803-010-0981-3

Freeman, B., Delhomme, M., Guthrie, D., \& Zhang, F. (1999). Vineland adaptive behaviour scale scores as a function of age and initial iq in 210 autistic children. Journal of Autism and Developmental Disorders, 29, 379-384. doi:10.1023/A:1023078827457

Guidetti, M., \& Tourrette, C. (1993). Evaluation de la communication sociale précoce ecsp. Issy-Les-Moulineaux: Editions Scientifiques et Psychologiques.

Jones, E. A., \& Carr, E. G. (2004). Joint attention in children with autism: Theory and intervention. Focus on Autism and Other Developmental Disabilities, 19, 13-26. doi:10.1177/10883576040190010301

Lawer, L., Brusilovsliy, E., Salzer, M. S., \& Mandell, D. S. (2009). Use the vocational rehabilitative services among adults with autism. Journal of Autism and Developmental Disorders, 39, 487-494. doi:10.1007/s10803-008-0649-4

Lord, C., Risi, S., Lambrecht, L., Cook Jr., E. H., Leventhal, B. L., DiLavore, P. C., Pickles, A., \& Rutter, M. (2000). The autism diagnostic observation schedule-generic: A standard measure of social and communicative deficits associated with the spectrum of autism. Journal of Autism Developmental Disorders, 30, 205-223.

Lord, C., Rutter, M., \& Le Couteur, A. (1994). Autism diagnostic interview revised: A revised version of a diagnostic interview for caregivers of individuals with possible pervasive developmental disor ders. Journal of Autism and Developmental Disorders, 24, 659-685.

Mawhood, L., Howlin, P., \& Rutter, M. (2003). Autism and developmental receptive language disorder: a comparative follow-up in early adult life. I: Cognitive and language outcomes. Journal of Child Psychology and Psychiatry, 41, 547-559. doi:10.1111/1469-7610.00642
Montreuil, N., \& Magerotte, G. (1994). Pratique de l'intervention individualisée. Bruxelles: De Boeck.

Mundy, P. (2007). Attention, joint attention, and social cognition. Current Directions in Psychological Science, 16, 269-274. doi:10.1111/j.1467-8721.2007.00518.x

Nadel, J. (2009). Où est le développement dans le syndrome developmental d'autisme? Enfance, 1, 101-108. doi:10.4074/S0013754509001128

Nichols, K. E., Fox, N., \& Mundy, P. (2005). Joint attention, self-recognition, and neurogognitive function in todlers. Infancy, 7, 35-51. doi:10.1207/s15327078in0701_4

Organisation Mondiale de la Santé (1994). CIM 10-Classification internationale des troubles mentaux et des troubles du comportement: Descriptions cliniques et directives pour le diagnostic. Paris: Masson.

Pry, R., \& Aussilloux, C. (2000). Le childhoodautism rating scales (cars) chez l'enfant autiste jeune: Analyse des items, étude des traits latents, validité concourante et généralisabilité. Psychologie et psychométrie, 21, 33-47.

Pry, R., Bodet J., Pernon, E., Aussilloux, C., \& Bagdadli, A. (2007). Initial characteristics of psychological development and evolution of the young autistic child. Journal of Autism and Developmental Disorders, 37, 341-353. doi:10.1007/s10803-006-0161-7

Pry, R., Guillain, A., \& Foxonet, C. (1996). Adaptation sociale et compétences sociocognitives chez l'enfant de 4-5 ans. Enfance, 3, 315329. doi:10.3406/enfan.1996.3030

Recordon-Gaboriaud, S. (2009). Les prises en charge de l'autisme, pratiques et recherches en France. Pratiques en Santé Mentale, 55, $11-17$.

Robins, D. L., Fein, D., Barton, M. L., \& Green, J. A. (2001). The modified checklist for autism in toddlers: An initial study investigating the early detection of autism and pervasive developmental disorders. Journal of Autism and Developmental Disorders, 31, 131-144. doi:10.1023/A:1010738829569

Rochat, P. (2001). The infant's world. Cambridge: Harward University Press.

Rogers, S., \& Benetto, L. (2002). Le fonctionnement moteur dans le cas de l'autisme. Enfance, 1, 63-73. doi:10.3917/enf.541.0063

Schopler, E., Reichler, R. J., DeVellis, R. F., \& Daly, K. (1980). Toward objective classification of childhood autism: Childhood Autism Rating Scale (CARS). Journal of Autism and Developmental Disorders, 10, 91-103. doi:10.1007/BF02408436

Seltzer, M. M., Shattuck, P, Abbetudo, L., \& Greenberg, J. S. (2004). Trajectory of development in adolescents and adults with autism. Mental Retardation Developmental Disabilities Research Review, 10, 234-247. doi: $10.1002 / \mathrm{mrdd} .20038$

Sparrow, S. S., Balla, D. A., \& Cicchetti, D. V. (1984). Vineland adaptive behavior scale. Circle Pines, MN: American Guidance Service.

Yirmiya, N., Gamliel. I., Pilowsky, T., Feldam, R., Baron-Cohen, S., \& Sigman, M. (2006). The development of siblings of children with autism at 4 and 14 months: Social engagement, communication, and cognition. Journal of Child Psychology and Child Psychiatry and Applied Disciplines, 47, 511-523. doi:10.1111/j.1469-7610.2005.01528.x 